has repeatedly been made by those associated with this section within the Institute of Psychiatry. We have emphasised the aetiological (Naguib et al, BJP, January 1987, 150, 124-127), symptomatological (Almeida et al, 1993), neuroradiological (Naguib \& Levy, 1987; Burns et al, 1989), logical and pragmatic basis for doing so (Almeida et al, 1992). The main points of difference are those of terminology and cut-off age, both of which may appear arbitrary at first sight.

We choose the term 'late paraphrenia' partly because of its historical associations, but mainly because it is immediately identifiable as different. The vicissitudes of its appearance and disappearance from the ICD system of classification and its potentially dire effect on case identification have been described elsewhere (Quintal et al, 1991), as have those of 'late-onset schizophrenia' in the DSM system from which it is about to disappear as an identifiable entity (Levy \& Almeida, 1993). This will make it difficult to separate these cases for more detailed studies, as they will be lumped together with schizophrenics who have grown old ('graduates').

The cut-off age has, to a certain extent, been a matter of taste, being 55 to 65 years in Europe and 45 years in the USA, but it need not be so. Some years ago, in a different context, a previous Editor of your journal (Slater, 1938) argued in favour of choosing the 'point of inversion' as that by which to separate 'involutional depression' from that occurring earlier in life. A similar point of inversion appears in age distribution by first admission for schizophrenia (Van Os et al, 1993): 65 years of age! There are, of course, more sophisticated mathematical techniques to clarify such issues, and we suggest that they should be applied to large series from different countries.

At a recent lively symposium on the topic at the Congress of the International Psychogeriatric Association in Berlin, several groups in Germany, Sweden, Denmark, Holland, the USA, and Canada appeared to have access to a sizeable number of cases. There was a clearly expressed wish to establish an international consortium to study some of the important and unanswered questions. Those who might be interested in joining such a consortium (minimum entry 40-50 well-documented cases) should get in touch with either of us, or with Dr Robert Howard at the address below.

Almitda, O. P.. Hoard, R., Förstl, H.. el al (1992) Late paraphrenia: a review. International Journal of Geriatric Psychiatry, 7 , 54.3-548.

(etcite In Functional Psychiatric Disorders in the Elderly (ed. E. Chiu). Cambridge: Cambridge University Press.
Burns, A., Carrick, J., Ames, D., et al (1989) The cerebral cortical appearance in late paraphrenia. International Journal of Geriatric Psychialry, 4, 31-34.

LEVY, R. \& ALMeIDA, P. (1993) ICD-10 for old age psychiatry. In The Royal College of Psychiatrists' Annual Meeting 1993 Abstract Booklet. London: The Royal College of Psychiatrists.

NAGUiB, M. \& LEVY, R. (1987) Late paraphrenia: neuropsychological impairment and structural brain abnormalities on computed tomography. International Journal of Geriatric Psychiatry. 2, 83-90.

Quintal, M., Day-Cody, D. \& Levy, R. (1991) Late paraphrenia and ICD-10. International Journal of Geriatric Psychiatry, 6, $111-116$

Slater, E. (1938) Zur erbpathologie des manisch-depressiven irrseins. Die elkern und kinder von manish-depressiven. Zeitschrift für die Gesmie Neurologie und Psychiatrie. 163, 1-47.

VAN Os, J., Galdos, P., LewIS, G., et al (1993) Schizophrenia sans frontieres: concepts of schizophrenia among French and British psychiatrists. British Medical Journal, 307, 489-492.

RAYMOND LEVY Osvaldo P. Almeida

Section of Old Age Psychiatry

Institute of Psychiatry

De Crespigny Park

Denmark Hill

London SE5 8AF

\section{Benzodiazepine fatal poisonings}

SIR: We are glad that Serfaty \& Masterton (BJP, September 1993, 163, 386-393) point out the important role of benzodiazepines in fatal poisonings. In 1990 we carried out a survey of drugs used in fatal self-poisonings in Switzerland (Michel et al, 1993), and we compared these findings (179 cases) with the drugs taken by suicide attempters over 12 months in the city and agglomeration of Berne (296 cases). We were surprised by the high number of benzodiazepines not only involved in attempted suicide (46 cases; $3 \%$ of all drugs taken, single or in combination with other drugs) but also in completed suicide (43 cases; $8 \%$ ). Flurazepam was the benzodiazepine used most frequently in both groups, being named on 16 death certificates as only drug, and on 12 certificates in combination with other drugs. In some but not all of these cases alcohol was involved.

Our findings are therefore consistent with those of Serfaty \& Masterton, and it is especially interesting that flurazepam which is still available in Switzerland appears to be the benzodiazepine with the greatest risk when taken in overdose. As could be expected, barbiturates were over-represented in fatal poisonings compared with non-fatal overdoses $\left(\chi^{2}=12.01\right.$, $P=0.001)$. There was no statistically significant difference in the distribution of antidepressants (although there was a trend towards relatively higher numbers in fatal poisonings), benzodiazepines, neuroleptics or non-opiate analgesics between the 
fatal and non-fatal overdoses. This, in our opinion, suggests that, for barbiturates, the toxicity of the drug plays an important role in the outcome of an overdose while this is much less the case in overdoses with other psychotropic drugs, including tricyclic antidepressants. However, our results also indicate that there are no truly 'safe' drugs when taken in overdose and in our opinion it is necessary to correct the misconception about the safety of benzodiazepines.

Michel, K., Arestegul, G. \& Spuhler, T. (1993) Suicide with psychotropic drugs in Switzerland. Pharmacopsychiatry (in press).

Universitätspoliklinik

3010 Berne, Switzerland

Swiss Federal Statistical Office

KONRAD MicheL

Switzerland

\section{Attachment theory}

SIR: Holmes' engaging review of the history of attachment theory and its relation to biology through ethology (BJP, October 1993, 163, 430-438) could have pointed to several other biological markers of interest to those 'brain scientists' who have kidnapped the term biological psychiatry.

Kraemer (1992) has presented details about the effects of different rearing patterns and attachment behaviour on brain amines and developing brain structure. He integrates the results in such a way that it is easy to conceptualise further bridges between the development of insecure-ambivalent attachment, depressive positions and treatment with antidepressants which have common biological pathways at brain systems level (here it is necessary to conceptualise the balance between the differing brain amines in systems terms).

Some of the tenets of evolutionary biology need to be considered in more detail in relation to 'secure attachment'. There is a danger that 'secure', will be equated with 'good/right'. Yet it is uncertain whether such attachment patterns will prepare children for their adult environments.

Similarly, it is essential to remember the qualitative marker of 'good enough' in this evolutionary perspective. Holmes presents an uncritical view of the maternal/psychotherapist attribute of attunement. As Winnicott (1971) pointed out, if the mother knows too well what the child is wanting, feeling or thinking, this is magic and has no place in the development of a therapeutic relationship.
Holmes could usefully have introduced readers in his review to the ways in which biological aspects of memory influence choice of therapeutic strategies within the attachment paradigm. With a greater awareness of these issues some of the 'equivalence paradox' to which he refers could be explored. Crittenden $(1992 a, b)$ has begun to do this in a way which colleagues in adult psychiatry may find useful for their practice. She highlights the usefulness of applying Tulving's three memory forms - the procedural, the semantic and the episodic (Tulving, 1985) - to understanding the ways in which life experiences will modify attachment behaviour on differing bases. The procedural memory form is preconscious, based on the ways in which children have been handled in the initial months. It is reflected in posture and bodily signs. It is at this level that it is particularly difficult to improve the lot of our patients with treatments which are not primarily behavioural or somatic in focus. It is particularly difficult to alter the behaviour of borderline personality through a primary focus on increasing reflexive self-awareness. One strategy is to influence the child's working model of his caregiver directly through short-term work with the mother, as shown by Murray \& Cooper (1993), referred to by Holmes.

In the first few years the child learns a way of accounting for his state, based on the way in which his condition is attributed to things happening around him. His semantic memory, based on the words applied by others, predominates. These biographical stories are retained and enlivened throughout childhood by the caregivers, but they do not necessarily coincide with the experiences which children subsequently have, and can reflect on themselves, stored in their episodic memory. Crittenden's suggestion is that cognitive-behavioural techniques are best suited to addressing problems associated with dissonance between semantic memory and episodic memory, whereas psychodynamic approaches are best suited to traumatic confusions in episodic memory. Clearly the degree to which distortions are present between the three memory types will present varying problems for producing a coherent, truly autobiographical account, in contrast to borrowed autobiographical accounts. Therefore, it is to be expected that therapy will have to address all memory levels. Kraemer's summary suggests how integration of the different therapy forms could also benefit from an understanding of brain amine changes and potential advantages of integrating physical treatments, such as with antidepressants, with the psychological.

My purpose in highlighting these additional points concerning the biology of attachment are to 